\title{
Categorical Nature of Consumer Price Estimations of Postharvest Bruised Apples
}

\author{
Yasushi Kyutoku $\mathbb{D}^{1},{ }^{1}$ Naoko Hasegawa, ${ }^{2}$ Ippeita Dan, ${ }^{3}$ and Hiroaki Kitazawa ${ }^{2}{ }^{2}$ \\ ${ }^{1}$ Research and Development Initiative, Chuo University, Bunkyo-ku 112-8551, Japan \\ ${ }^{2}$ Food Research Institute, National Agriculture and Food Research Organization, Tsukuba 305-8642, Japan \\ ${ }^{3}$ Department of Integrated Science and Engineering for Sustainable Society, Chuo University, Bunkyo-ku, Tokyo 112-8551, Japan
}

Correspondence should be addressed to Hiroaki Kitazawa; ktz@affrc.go.jp

Received 28 May 2018; Revised 2 October 2018; Accepted 10 October 2018; Published 6 November 2018

Academic Editor: Antonio Piga

Copyright ( 2018 Yasushi Kyutoku et al. This is an open access article distributed under the Creative Commons Attribution License, which permits unrestricted use, distribution, and reproduction in any medium, provided the original work is properly cited.

\begin{abstract}
Postharvest fruits are susceptible to damage which eventually results in large product and financial losses. While abundant studies have been conducted to objectively index the severity of such damage, how consumers subjectively assess the severity of damaged apples has been understudied. Previous studies have indicated that consumers' aesthetic devaluation of product quality is reflected in estimated price. Thus, the current online questionnaire study was conducted to examine the effect of objectively indexed severity of damage on consumers' subjective price estimations. Four hundred thirty-nine consumers of apples were asked to estimate the market price for apples in photographic images of 1 or 3 "Orin" ("Golden Delicious" × "Indo") apples at 9 levels of severity of damage. A 2 (1- and 3-piece) $\times 9$ (severity of damage) within ANCOVA with reference price as a covariate indicated significant two-way interaction between the number of apples and severity of damage on estimated price. Consequently, the 1- and 3-piece conditions were examined separately. The results of both analyses indicate a categorical rather than quantitative, continuous reduction in estimated price.
\end{abstract}

\section{Introduction}

The Japanese government has encouraged the consumption of fruits for a healthy diet due to their high nutritional value, including fiber, minerals, and vitamins [1]. Apples are among the most consumed fruits in Japan [2]. After harvest, controlled-atmosphere storage systems preserve apples, which can maintain their freshness for more than 6 months [3]. The surfaces of apples are susceptible to postharvest mechanical damage during handling and transportation $[4,5]$. One of the most commonly observed forms of surface damage is bruising $[4,5]$, which leads to large product and financial losses throughout the industry. Eventually, bruises lead to fungal infections such as gray (Botrytis) and blue (Penicillium) mold [6] and allochroism. Even when the apples are fit for consumption, the reduction in value due to aesthetic damage is substantial [7]. For instance, bruised apples are usually sold in industrial markets where the price of an apple is substantially reduced compared with retailmarket prices [6].

In the retail market, the cosmetic appearance of an apple, such as color, shape, and damage, is directly related to a consumer's evaluation of the product's quality $[8,9]$ which is to say that the subjective evaluation of the quality of an apple is strongly related to its appearance [10-12]. Because postharvest bruising is related to large product and financial losses, abundant studies on bruise prevention, such as improved transportation techniques, from the viewpoint of suppliers have been conducted [6]. For instance, various researchers have examined physical factors related to damage such as packaging friction $[6,13]$, vibration $[14,15]$, and shock [16-18]. However, little research has focused on consumers' subjective evaluations of the quality of damaged products [11] and reported an association between visual attention to damaged apples and purchase intention. Another study by Kim and House [19] reported that large 
surface damage to grapefruits substantially lowers consumers' willingness to pay. There are very few studies that have incorporated consumers' subjective evaluations of apples in conjunction with objectively indexed damage. Because consumers' subjective evaluations of product quality are known to be reflected in estimated prices [20], the current study examined the effect of objectively engineered damage to the surfaces of apples on consumers' estimation of their prices.

It is highly possible that an objective index of the severity of surface damage to apples $[4,5]$ does not correspond to consumers' subjective evaluations of product quality because the latter does not scale at a constant rate, as does the former. Rather, the consumer's subjective evaluations should be organized into graded categories as we tend to simplify information in a graded manner for quantitative visual stimuli because we cannot distinguish subtle differences $[21,22]$. It should be noted that consumers' expectations for the pricing of products are influenced by their reference price, which is the price they have internalized as normal based on past experience [23-25]; they should tend to devalue the damaged product compared with their reference price for the undamaged one. Further, because apples are sold individually or in multiple-piece packages at grocery stores in Japan, we were curious about whether consumers' devaluation of damaged products would differ with the number of pieces packaged together. According to Ahmetoglu et al.'s review study on pricing [26], consumers are expected to anticipate lower prices for multiple-piece packages of apples because bundled items signal discount. In the same way, consumers demand greater compensation for bundled products that are damaged [27].

These facts, findings, and questions led us to define the twofold purpose of the current study. First, we aimed to confirm that consumers use self-reported typical purchase price as a reference price. Second, we assessed the effect of damage on estimated prices for photographically displayed apples (1- or 3-piece) with consumers' reference prices as a covariate. In doing so, we explored the relationship between the effect of objectively indexed surface damage of apples on consumers' subjective price estimations for the corresponding apples. Here, we aimed to propose an evidence-based strategy that may prevent excessive devaluation of bruised apples.

\section{Materials and Methods}

2.1. Participants and Procedure. Four hundred thirty-nine consumers of apples $\left(\mu_{\text {age }}=44.8, \mathrm{SD}=13.62, M d_{\text {purchase- }}\right.$ frequency $=$ more than once a month; Table 1$)$ were randomly recruited from a Japanese online research company $\left(N_{\text {par- }}\right.$ ticipant pool $>3.6$ million) who met the following recruiting criteria: (1) aged over 20 and (2) at least one annual purchase of an apple. After agreeing to the terms of the study with informed consent, participants proceeded to the participant characteristics questionnaire (age, gender, employment status, and purchase frequency of apples). Then, they were asked to estimate the market price (estimated price) for 1 or 3 yellow-green "Orin" apples in the free-answer format
TABle 1: Participant characteristics.

\begin{tabular}{lc}
\hline Demographics & $N(\%)$ \\
\hline Gender & \\
Male & $191(45.1 \%)$ \\
Female & $248(54.9 \%)$ \\
\hline Employment & \\
Full time & $234(53.3 \%)$ \\
Part time & $52(11.8 \%)$ \\
Unemployed/retired & $53(12.1 \%)$ \\
Housewife/househusband & $91(21.0 \%)$ \\
Experiential purchase price for & Mean (SD) \\
a single apple (reference price) & $¥ 117.5(45.8)$ \\
\hline
\end{tabular}

Note. Six outliers were eliminated from this table. Monthly currency exchange rate for Aug 2016 was $¥ 100=\$ 0.99$.

based on photographic images presenting apples with 9 different levels of damage: 0 (normal apple), 6, 7, 8, 9, 10, 11, 12 , and 13 (the area of the apple's surface that is damaged; each number represents $\times 10^{-4} \mathrm{~m}^{2}$ of damage) (Figure 1). Damage severity levels 1 to $5 \times 10^{-4} \mathrm{~m}^{2}$ were not used for the current study due to technical difficulties with consistently setting up damages for those levels. Photographic images corresponding to each level of damage were randomly shown 3 times for each piece count (1 and 3 apples). The presentation order of the photographic images was randomized. Finally, participants provided the average purchase price of a single apple based on their daily grocery shopping experience (reference price) in response to a freeanswer-format question (six participants, who provided extremely high experiential purchase prices for a single apple $(\mathrm{SD}>3.29)$, were eliminated as outliers in order to exclude nonrepresentative consumers of apples). The entire procedure took approximately 20 minutes. The study was approved by the institutional ethics committee of the National Food Research Institute (HU2015-1).

2.2. Materials and Stimuli Checks. The apples in photographs for each level of damage were randomly selected to control for differences in surface color (Figure 1). Damage was inflicted on each apple using a shock tester with a cushioning adjusting system (SDST-300 and SVS-300, Shinyei Testing Machinery, Japan) set to various shock conditions based on [28] (Figure 2 and Table 2). The area of damage $\left(\times 10^{-4} \mathrm{~m}^{2}\right)$ was estimated using the following equation [29]:

$$
\text { damage area }=\frac{\left(W_{1} \times W_{2} \times \pi\right)}{4},
$$

where $W_{1}$ and $W_{2}$ represent damage widths along the major and minor axes, and $\pi$ the circle ratio. The shock conditions for damaging the apples were the same as those described in a previous study, and thus, the severity of the damage of each fruit in this study corresponded to that of the previous study [28]. An Olympus E-30 camera with a standard lens (Zuiko Digital 14-54 mm f2.8-3.5 II; Olympus, Japan) was used to take photographs in the autofocus shooting mode.

Internal consistency for 3 photographs at each level of damage for 1 and 3 apples indicated sufficient reliability of 


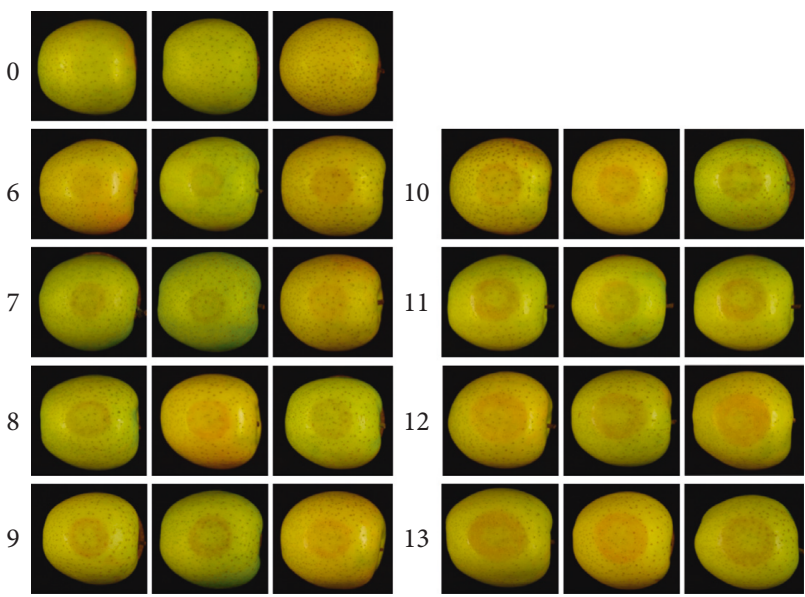

FIgUre 1: Apple photographs used in the questionnaire. Note. The numbers to the left of each photograph stand for the severity of the damage estimated by area $\left(\times 10^{-4} \mathrm{~m}^{2}\right)$.

price estimation for all severities of damage (smallest Cronbach's $\alpha=0.91$ for 1 piece; smallest Cronbach's $\alpha=$ 0.93 for 3 pieces).

The following preliminary analyses were conducted before the main analyses.

First, it was important that participants be familiar with market prices at the time of the study (114.6 yen) [30], in order to collect credible responses. Therefore, each participant's experiential purchase (reference) price for a single apple (Table 1) was compared with the market price to verify that their responses would be credible [31]. Thus, a onesample $t$-test against 114.6 yen was conducted against reference prices, and there was little difference $(t(438)=1.31$, $p=0.19, d=0.05)$, supporting the idea that the current participants were representative Japanese apple consumers in terms of familiarity with purchase price. Next, to explore potential covariates of estimated price, correlations between demographics and reference prices were explored. None of the demographics or self-reported purchase-related variables were associated with estimated prices (largest $r(439)=0.06, p>0.30)$. Therefore, demographic variables were not used as covariates in the subsequent analyses.

2.3. Statistical Analyses. To ascertain that consumers' estimations were based on their past shopping experience, a paired $t$-test was conducted. No difference was expected between a participant's experiential purchase (reference) price for an apple and their estimated price for a 0-damage apple. Then, a 2 (1- or 3 -piece) $\times 9$ (severity of damage) within ANCOVA with reference price for a single apple as the covariate was conducted to examine whether the 1- and 3-piece conditions, respectively, exhibited different patterns of estimated price reduction. Due to the significant interaction, a one-way within ANCOVA was conducted for photographic images of apples from the 1- and 3-piece conditions separately to examine the effect of damage severity with reference price as a covariate. If a main effect of damage severity was observed, post hoc comparison using the Sidak-Bonferroni procedure was conducted for each

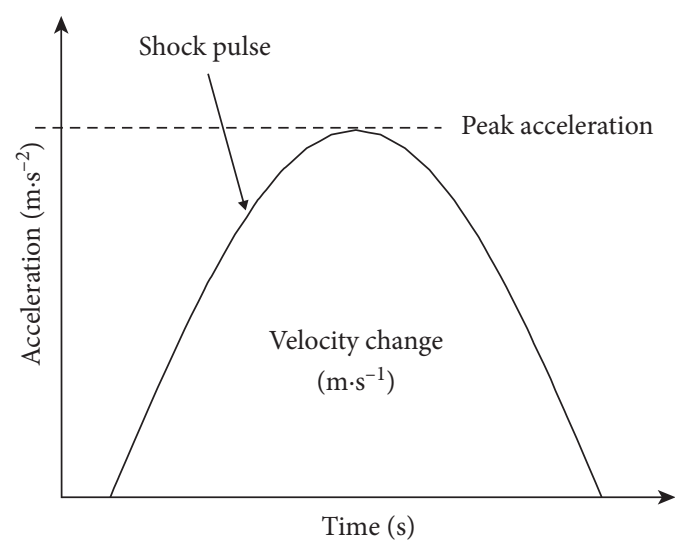

Figure 2: Relationship between time, peak acceleration, and velocity change for a half-sine shock pulse.

TABLE 2: Relationship between velocity change, peak acceleration, and the damage area of apples.*

\begin{tabular}{|c|c|c|}
\hline $\begin{array}{l}\text { Velocity change } \\
\left(\mathrm{m} \cdot \mathrm{s}^{-1}\right)\end{array}$ & $\begin{array}{l}\text { Peak acceleration } \\
\left(\mathrm{m} \cdot \mathrm{s}^{-2}\right)\end{array}$ & Damage area $\left(\times 10^{-4} \mathrm{~m}^{2}\right)$ \\
\hline 2.5 & 490.3 & 6 \\
\hline 2.5 & 588.4 & 7 \\
\hline 2.5 & 686.5 & 7 \\
\hline 2.5 & 784.5 & 8 \\
\hline 2.5 & 1372.9 & 9 \\
\hline 3.0 & 392.3 & 6 \\
\hline 3.0 & 490.3 & 7 \\
\hline 3.0 & 588.4 & 8 \\
\hline 3.0 & 686.5 & 8 \\
\hline 3.0 & 784.5 & 9 \\
\hline 3.0 & 882.9 & 10 \\
\hline 3.0 & 980.7 & 10 \\
\hline 3.5 & 392.3 & 6 \\
\hline 3.5 & 490.3 & 7 \\
\hline 3.5 & 588.4 & 8 \\
\hline 3.5 & 686.5 & 10 \\
\hline 3.5 & 784.5 & 10 \\
\hline 3.5 & 882.9 & 11 \\
\hline 3.5 & 980.7 & 11 \\
\hline 4.0 & 392.3 & 7 \\
\hline 4.0 & 490.3 & 7 \\
\hline 4.0 & 588.4 & 9 \\
\hline 4.0 & 686.5 & 10 \\
\hline 4.0 & 784.5 & 11 \\
\hline 4.0 & 882.9 & 12 \\
\hline 4.0 & 980.7 & 12 \\
\hline 4.5 & 392.3 & 7 \\
\hline 4.5 & 490.3 & 8 \\
\hline 4.5 & 588.4 & 10 \\
\hline 4.5 & 686.5 & 10 \\
\hline 4.5 & 784.5 & 11 \\
\hline 4.5 & 882.9 & 13 \\
\hline 4.5 & 980.7 & 13 \\
\hline 5.0 & 392.3 & 7 \\
\hline 5.0 & 490.3 & 9 \\
\hline 5.0 & 588.4 & 10 \\
\hline 5.0 & 686.5 & 10 \\
\hline 5.0 & 784.5 & 12 \\
\hline 5.0 & 980.7 & 13 \\
\hline
\end{tabular}

*Each datum was obtained from a previous study [28]. For velocity change and peak acceleration, refer to Figure 2. 
neighboring severity of damage. Only meaningful differences, Cohen's $d \geq 0.20$, were subsequently interpreted.

\section{Results}

The paired $t$-test examining whether the reference and estimated prices for a 0 -damage apple differed revealed, as expected, that there was no significant difference $(t(438)=1.28, p=0.21, d=0.06)$.

The 2 (1- and 3-piece) $\times 9$ (severity of damage) within ANCOVA with reference price as the covariate revealed a significant two-way interaction between the number of pieces and the severity of damage on estimated price: $F(8,3456)=6.25, \quad p<0.001$, and $\eta_{p}^{2}=0.03$ (Figure 3). Consequently, 1- and 3-piece conditions were examined separately.

A one-way within ANCOVA was conducted to examine the effect of severity of damage on estimated price for the 1piece condition with reference price as the covariate. There was a main effect of severity of damage: $F(8,3480)=36.51$, $p<0.001$, and $\eta_{p}^{2}=0.08$ (Figure 3 ). There was a reduction in estimated price between damage severities of 0 and 6 $(p<0.001, d=1.19), 7$ and $8(p<0.001, d=0.43)$, and 11 and $12(p<0.001, d=0.28)$, indicating categorical rather than quantitative reductions in estimated prices. Thus, estimated prices did not steadily decrease at each point with the objective damage index for the 1-piece condition.

A one-way within ANCOVA was conducted to examine the effect of damage on estimated price for the 3-piece condition with reference price as the covariate. There was a main effect of severity of damage: $F(8,3472)=16.89$, $p<0.001$, and $\eta_{p}^{2}=0.04$ (Figure 3 ). There was a reduction in estimated price between damage severities of 0 and 6 $(p<0.001$ and $d=0.98), 7$ and $8(p<0.001$ and $d=0.45), 8$ and $9(p<0.001$ and $d=0.20)$, and 12 and $13(p<0.001$ and $d=0.28$ ), indicating categorical rather than quantitative reductions in estimated prices. Estimated prices did not steadily decrease at each point with the objective damage index for the 3 -piece condition, as with the 1-piece condition.

\section{Discussion}

Despite the great amount of effort put into and many advancements in postharvest technology to prevent fungal infections and to extend shelf life $[32,33]$, cosmetic defects such as bruising are unavoidable in the fresh-fruit market [34]. Such damage is associated with a reduction of the quality of fresh products, which leads to large product and financial losses [5]. Therefore, understanding the way consumers estimate prices for bruised fruits in relation to objectively indexed damage severity is crucial in order to adequately price damaged products and avoid unnecessary profit losses. The purpose of the current study was twofold: we first examined whether the daily purchase (reference) price of apples is associated with the estimated price and second examined the association between objectively measured, manually produced surface damage of apples [28], and prices estimated by consumers. To the authors' knowledge, this is the first study to incorporate consumers'

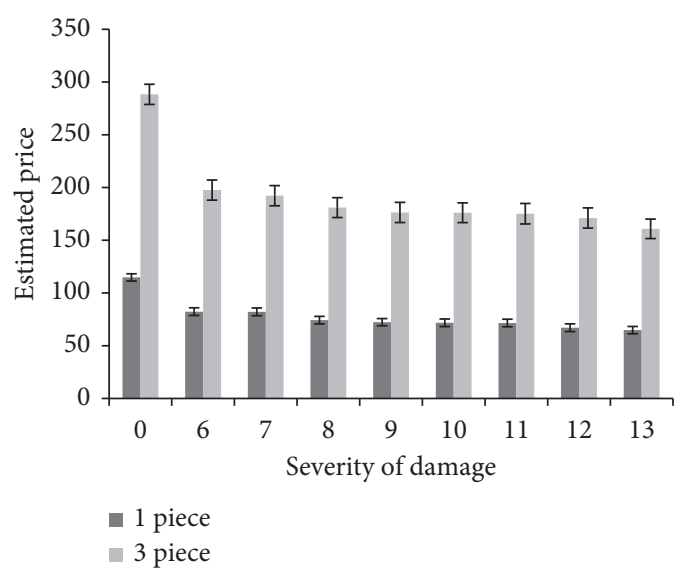

FIgURE 3: Estimated prices of 1 and 3 apples. Error bar represents a $95 \%$ confidence interval.

subjective evaluation of apples in conjunction with objectively indexed damage.

Regarding the first objective, as expected, consumers' reference prices were based on their daily purchase experiences [23-25]. This implies that retailers should use their standard price for a normal apple as a baseline price. As for the second objective, price reductions appeared to occur in graded categories rather than in a continuous progression at each severity of damage. This is consistent with previous findings for other cognitive processes [21, 22]. The price reductions estimated by consumers from undamaged to damaged apples were at most one-third regardless of the number of pieces. However, there were slightly different patterns of estimated price reductions for the 1- and 3-piece conditions. Specifically, a greater number of points of price reduction were found for the 3-piece compared with the 1-piece condition as in Ahmetogly et al.'s review [26]. This might be attributed to consumers being more sensitive to defects among a larger number of pieces compared with a single piece as reported [27]. These results together indicate that while damaged apples were regarded as viable merchandise, there was a significant reduction in estimated prices between damaged and undamaged apples rather than among apples with different severities of damage. As for packaging and transportation, effort and resources should be allocated to avoid any damage at all rather than merely alleviating damage because even a small amount of damage is associated with substantial devaluation. As for retailers, consumers expect lower prices for damaged apples, especially those that are sold as multiple pieces.

The limitations of the current study are as follows. First, less severe damage levels should be incorporated into a future study: the effect size between no damage and the first level of damage severity may be reduced if smaller severities of damage could be reliably reproduced. Further, consumers' willingness to pay should be measured in addition to estimated prices in order to examine the market demand for damaged apples.

\section{Conclusion}

In conclusion, the current study demonstrates that consumers' reference prices are based on their daily purchase 
experiences. Additionally, these results imply a qualitative rather than quantitative reduction in estimated pricing as damage increases. While a greater number of points of price reduction were found for the 3-piece condition, what matters to the consumer appears to be whether an apple is "damaged or not", rather than "how damaged" it is. The current findings will contribute to the elucidation of the value of damaged apples from the consumer's perspective. Further studies that incorporate both objective and subjective indices of damage should be conducted to extend the current findings to apples in general, fruits, and possibly to other food products.

\section{Data Availability}

The data used to support the findings of this study are available from the corresponding author upon request.

\section{Conflicts of Interest}

The authors declare that they have no conflicts of interest.

\section{Acknowledgments}

This study was supported by a Grant-in-Aid for Young Scientists (B) (No. 26850160) from the Japan Society for the Promotion of Science (JSPS).

\section{References}

[1] Ministry of Agriculture, Foresty, and Fisheries of Japan, "Guidelines for food life," http://www.maff.go.jp/j/syokuiku/ shishinn.html, 2016.

[2] Ministry of Internal Affairs and Communications, "Family budget inquiry," http://www.stat.go.jp/data/kakei/, 2016.

[3] A. Rocha, M. C. Nunes, A. Morais, and M. M. De Bernado, "Effects of controlled atmosphere on quality of minimally processed apple (cv. Jonagored)," Journal of Food Processing and Preservation, vol. 24, no. 6, pp. 435-451, 2000.

[4] Z. Li and C. Thomas, "Quantitative evaluation of mechanical damage to fresh fruits," Trends in Food Science and Technology, vol. 35, no. 2, pp. 138-150, 2014.

[5] U. L. Opara and P. B. Pathare, "Bruise damage measurement and analysis of fresh horticultural produce: a review," Postharvest Biology and Technology, vol. 91, pp. 9-24, 2014.

[6] M. Van Zeebroeck, H. Ramon, J. De Baerdemaeker, B. Nicolaï, and E. Tijskens, "Impact damage of apples during transport and handling," Postharvest Biology and Technology, vol. 45, no. 2, pp. 157-167, 2007.

[7] J. C. Buzby, J. Hyman, H. Stewart, and H. F. Wells, “The value of retail-and consumer-level fruit and vegetable losses in the United States," Journal of Consumer Affairs, vol. 45, no. 3, pp. 492-515, 2011.

[8] R. Moser, R. Raffaelli, and D. Thilmany-McFadden, "Consumer preferences for fruit and vegetables with credencebased attributes: a review," International Food and Agribusiness Management Review, vol. 14, no. 2, pp. 121-142, 2011.

[9] C. Yue, H. H. Jensen, D. S. Mueller, G. R. Nonnecke, D. Bonnet, and M. L. Gleason, "Estimating consumers' valuation of organic and cosmetically damaged apples," HortScience, vol. 42, no. 6, pp. 1366-1371, 2007.
[10] S. Arivazhagan, R. N. Shebiah, S. S. Nidhyanandhan, and L. Ganesan, "Fruit recognition using color and texture features," Journal of Emerging Trends in Computing and Information Sciences, vol. 1, no. 2, pp. 90-94, 2010.

[11] S. R. Jaeger, L. Antúnez, G. Ares, J. W. Johnston, M. Hall, and F. R. Harker, "Consumers' visual attention to fruit defects and disorders: a case study with apple images," Postharvest Biology and Technology, vol. 116, pp. 36-44, 2016.

[12] V. Leemans and M.-F. Destain, "A real-time grading method of apples based on features extracted from defects," Journal of Food Engineering, vol. 61, no. 1, pp. 83-89, 2004.

[13] G. L. Barchi, A. Berardinelli, A. Guarnieri, L. Ragni, and C. T. Fila, "Damage to loquats by vibration-simulating intrastate transport," Biosystems Engineering, vol. 82, no. 3, pp. 305-312, 2002.

[14] V. Chonhenchob, S. Sittipod, D. Swasdee, P. Rachtanapun, S. Singh, and J. A. Singh, "Effect of truck vibration during transport on damage to fresh produce shipments in Thailand," Journal of Applied Packaging Research, vol. 3, no. 1, pp. 27-38, 2009.

[15] B. Soleimani and E. Ahmadi, "Evaluation and analysis of vibration during fruit transport as a function of road conditions, suspension system and travel speeds," Engineering in Agriculture, Environment and Food, vol. 8, no. 1, pp. 26-32, 2015.

[16] Y. Ishikawa, H. Kitazawa, and T. Shiina, "Vibration and shock analysis of fruit and vegetables transport -Cherry transport from Yamagata to Taipei-," Japan Agricultural Research Quarterly, vol. 43, no. 2, pp. 129-135, 2009.

[17] H. Kitazawa, K. Saito, and Y. Ishikawa, "Effect of difference in acceleration and velocity change on product damage due to repetitive shock," Packaging Technolgy and Science, vol. 27, no. 3, pp. 221-230, 2014.

[18] E. Yasunaga, S. Fukuda, M. Nagle, and W. Spreer, "Effect of storage conditions on the postharvest quality changes of fresh mango fruits for export during transportation," Environmental Control in Biology, vol. 56, no. 2, pp. 39-44, 2018.

[19] H. Kim and L. A. House, "The impact of cosmetic defects on Japanese consumers' preference for fresh grapefruit," Journal of International Food and Agribusiness Marketing, vol. 24, no. 3, pp. 201-212, 2012.

[20] X. Li, S. Jervis, and M. Drake, "Examining extrinsic factors that influence product acceptance: a review," Journal of Food Science, vol. 80, no. 5, pp. S1083-S1092, 2015.

[21] I. Douven, "Vagueness, graded membership, and conceptual spaces," Cognition, vol. 151, pp. 80-95, 2016.

[22] I. Douven, S. Wenmackers, Y. Jraissati, and L. Decock, "Measuring graded membership: the case of color," Cognitive Science, vol. 41, no. 3, pp. 686-722, 2017.

[23] L. E. Bolton, L. Warlop, and J. W. Alba, "Consumer perceptions of price (un) fairness," Journal of Consumer Research, vol. 29, no. 4, pp. 474-491, 2003.

[24] L. L. Cheng and K. B. Monroe, "An appraisal of behavioral price research (part 1): price as a physical stimulus," AMS Review, vol. 3, no. 3, pp. 103-129, 2013.

[25] A. O. Peschel, S. Zielke, and J. Scholderer, "Reference price formation for product innovations-the role of consistent price-value-relationships," Proceedings in System Dynamics and Innovation in Food Networks 2016, pp. 101-103, 2016.

[26] G. Ahmetoglu, A. Furnham, and P. Fagan, "Pricing practices: a review of their effects on consumer perceptions and behaviour," Journal of Retailing and Consumer Services, vol. 21, no. 5, pp. 696-707, 2014. 
[27] F. Shaddy and A. Fishbach, "Seller beware: how bundling affects valuation," Journal of Markeitng Research, vol. 54, no. 5, pp. 737-751, 2017.

[28] H. Kitazawa, N. Hasegawa, and Y. Tsukakoshi, "Evaluation of the relationship between shock and bruise area of apple fruit," Food Science and Technology Research, vol. 22, no. 4, pp. 485-489, 2016.

[29] F. Lu, Y. Ishikawa, H. Kitazawa, and T. Satake, "Measurement of impact pressure and bruising of apple fruit using pressuresensitive film technique," Journal of Food Engineering, vol. 96, no. 4 , pp. 614-620, 2010.

[30] Statistics Bureau of Japan, Average Retail Price of Primary Items, Statistics Bureau of Japan, Tokyo, Japan, http://www. stat.go.jp/data/kouri/doukou/3.html, 2013.

[31] V. Aalto-Setälä and A. Raijas, "Actual market prices and consumer price knowledge," Journal of Product and Brand Management, vol. 12, no. 3, pp. 180-192, 2003.

[32] M. A. De León-Zapata, A. Sáenz-Galindo, R. Rojas-Molina, R. Rodríguez-Herrera, D. Jasso-Cantú, and C. N. Aguilar, "Edible candelilla wax coating with fermented extract of tarbush improves the shelf life and quality of apples," Food Packaging and Shelf Life, vol. 3, pp. 70-75, 2015.

[33] H. Morales, S. Marín, A. J. Ramos, and V. Sanchis, "Influence of post-harvest technologies applied during cold storage of apples in Penicillium expansum growth and patulin accumulation: a review," Food Control, vol. 21, no. 7, pp. 953-962, 2010.

[34] N.-N. Wang, D.-W. Sun, Y.-C. Yang, H. Pu, and Z. Zhu, "Recent advances in the application of hyperspectral imaging for evaluating fruit quality," Food Analytical Methods, vol. 9, no. 1, pp. 178-191, 2016. 


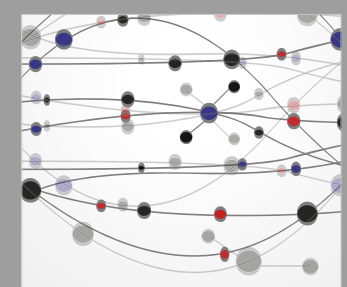

The Scientific World Journal
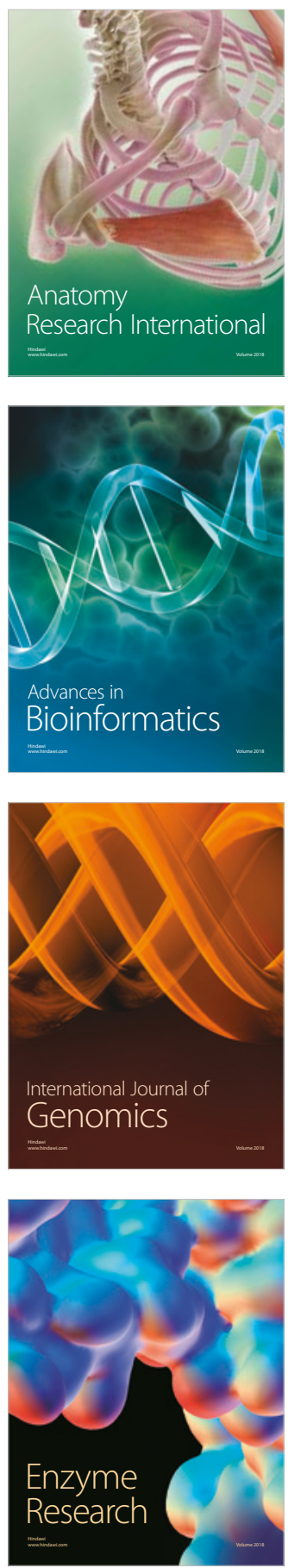
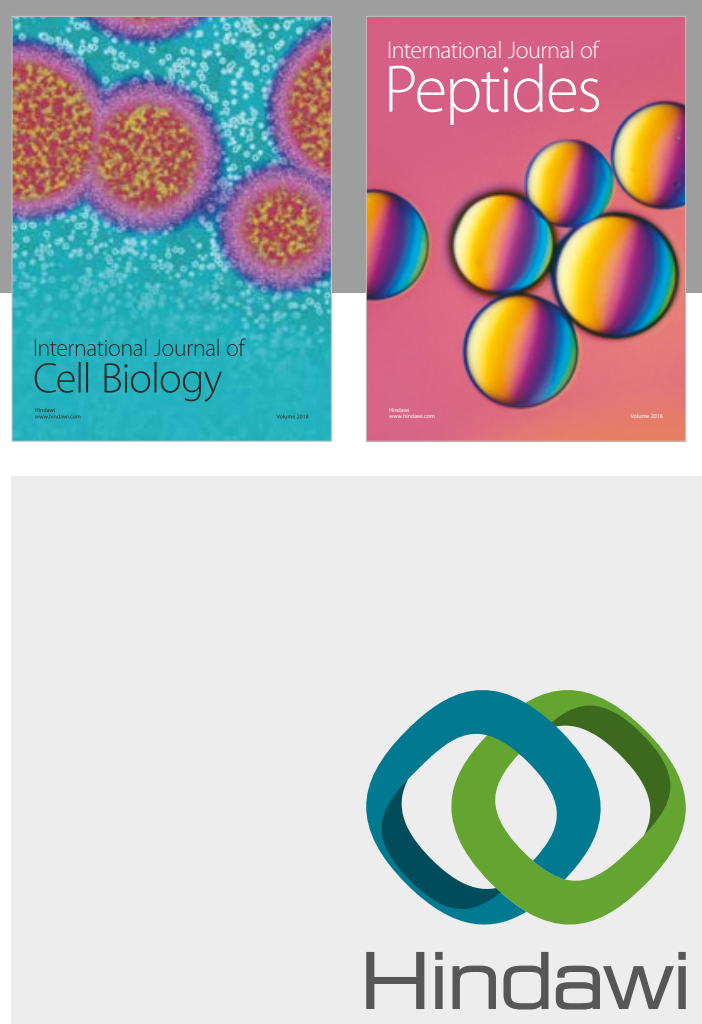

Submit your manuscripts at

www.hindawi.com
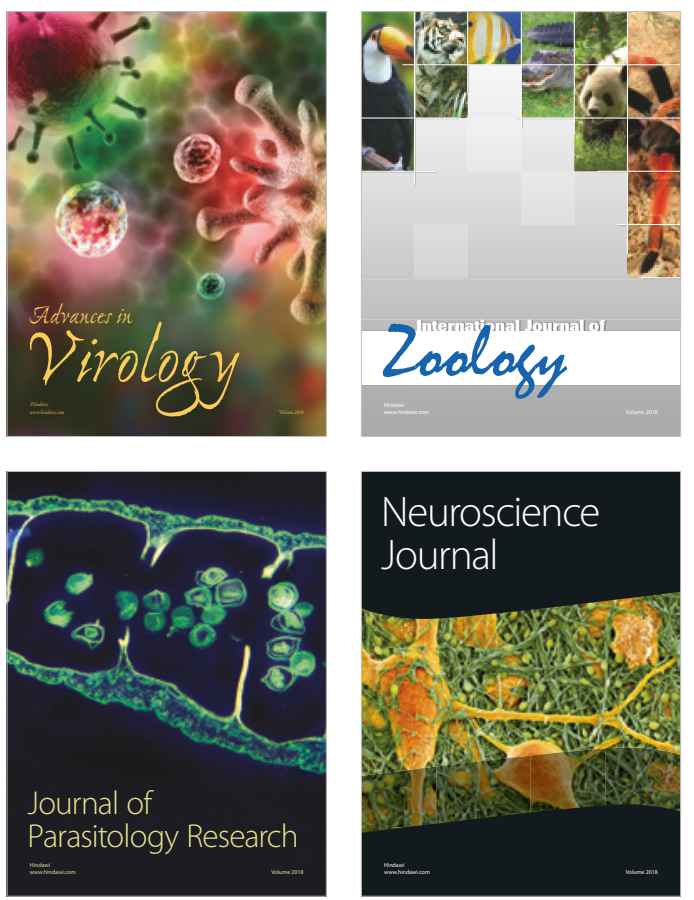
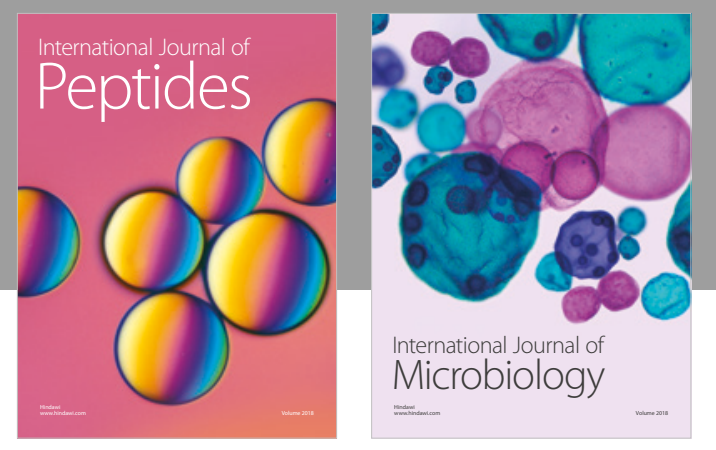

nternational Journal of Microbiology
Journal of
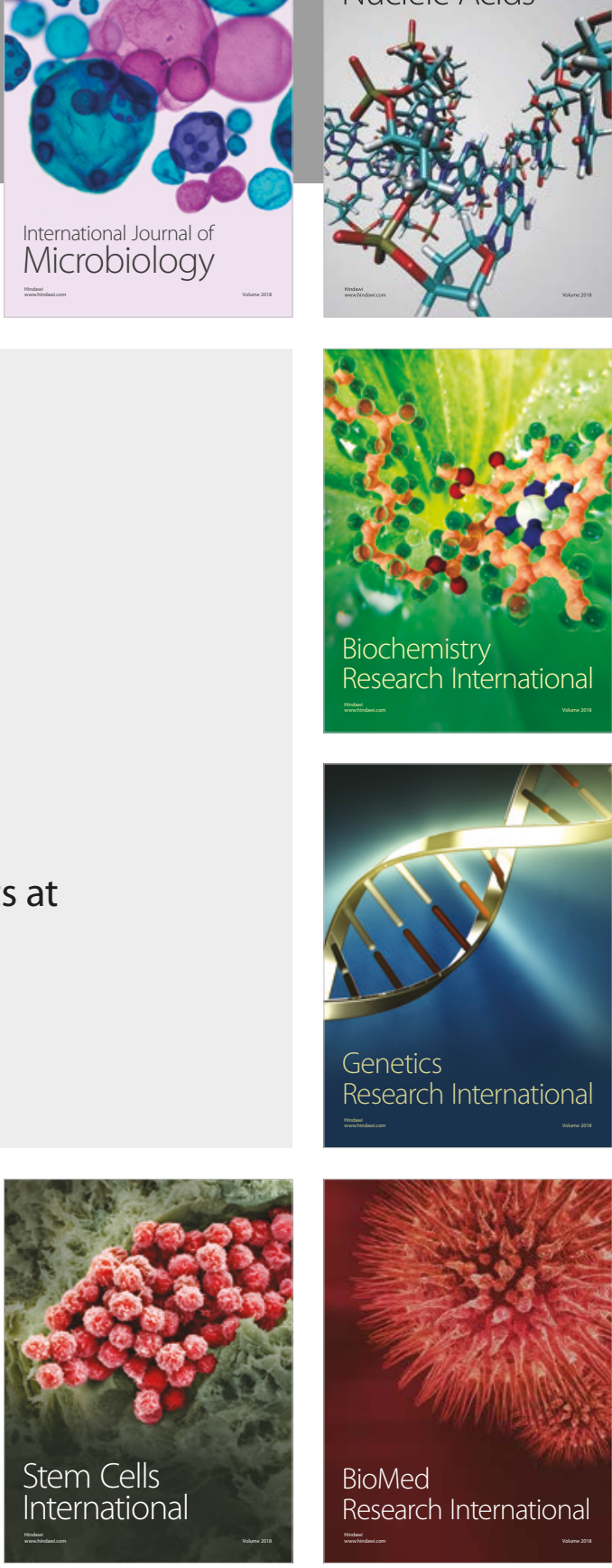
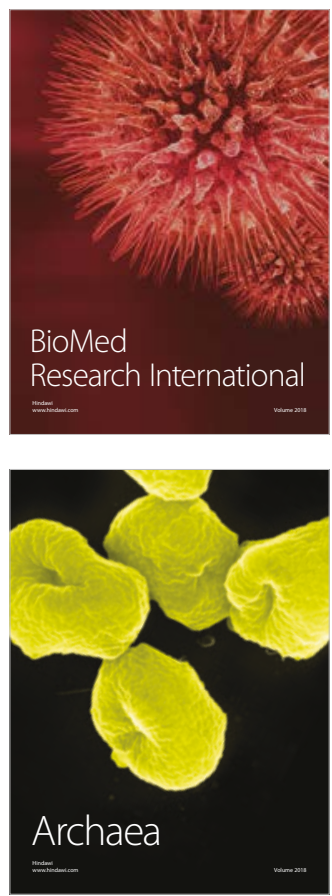